\title{
HUBUNGAN METODE PENYULUHAN SMALL GROUP DISCUSSION (SGD) DENGAN TINGKAT PENGETAHUAN ANEMIA PADA IBU HAMIL DI RUMAH BERSALIN GEBANG MEDIKA KOTA TANGERANG
}

\author{
Eka Mardiana Afrilia', Heliyanah Sari ${ }^{2}$ \\ Fakultas Ilmu Kesehatan \\ Universitas Muhammadiyah Tangerang \\ Email:eka@fikes-umt.ac.id
}

\begin{abstract}
ABSTRAK
Anemia sebagai salah satu masalah gizi di Indonesia yang harus di tangani secara serius, terutama pada anemia gizi, Prevalensi anemia besi ibu hamil yang tinggi dapat disebabkan oleh tingkat kepatuhan minum tablet besi yang rendah (20-30\%). Hubungan Metode Penyuluhan Small Group Discussion dengan Tingkat Pengetahuan Anemia Pada Ibu Hamil di Rumah Bersalin Gebang Medika Kota Tangerang Tahun 2017. Rancangan Penelitian ini menggunakan metode survey analitik dengan pendekatan cross sectional. Penelitian ini bersifat analisis bivariat untuk mengetahui Hubungan Metode Penyuluhan Small Group Discussion dengan Tingkat Pengetahuan Anemia Pada Ibu Hamil di Rumah Bersalin Gebang Medika Kota Tangerang Tahun 2017. Data yang digunakan adalah data primer yang diperoleh melalui kuesioner dengan 45 populasi ibu tentang anemia sebanyak 45 sample. Dari hasil penelitian menggunakan uji Chi Square yang diolah menggunakan program SPSS 20.0 diketahui bahwa distribusi frekuensi pengetahuan didapat 23 (55.6\%) dengan pengetahuan baik, pendidikan didapatkan 27 responden $(60 \%)$ dengan pendidikan tinggi, pekerjaan $23(51.1 \%)$ tidak bekerja, paritas $26(57.8 \%)$ dengan primipara, terdapat Hubungan Metode penyuluhan Small Group Discussion (SGD) Dengan Tingkat Pengetahuan Anemia Pada Ibu Hamil. Dari hasil penelitian ini dapat disimpulkan bahwa masih banyaknya pengetahuan ibu yang kurang tentang anemia, saran peneliti kepada tenaga kesehatan untuk lebih aktif lagi dalam memberikan infomasi dan penyuluhan tentang anemia dan cara pencegahan serta penanganannya.
\end{abstract}

Kata kunci : SGD, Pengetahuan, Anemia

\begin{abstract}
Anemia as one of the nutritional problems in Indonesia that must be handled seriously, especially in nutritional anemia, The high prevalence of iron anemia in pregnant women can be caused by low iron tablets compliance rate (20-30\%). Relationship of Small Group Discussion Guidance Method with Level of Knowledge of Anemia in Pregnant Women at Gebang Meditation Hospital of Tangerang City City in 2017. This research design use analytical survey method with cross sectional approach. This research is bivariate analysis to know the Relation Method of Small Group Discussion with Knowledge Level of Anemia in Pregnant Women at Gebang Medika Hospital of Tangerang City in 2017. Data used is primary data obtained through questionnaire with 45 population of mother about anemia as much as 45 sample. From result of research using Chi Square test which processed using SPSS
\end{abstract}


20.0 program known that knowledge frequency distribution got 23 (55.6\%) with good knowledge, education got 27 respondents (60\%) with higher education, job 23 (51.1\%) did not work, parity 26 (57.8\%) with primipara, there is a Relation Method Small Group Discussion (SGD) With Anemia Knowledge Level In Pregnant Women. From the results of this study can be concluded that there is still a lot of knowledge of mothers who are less about anemia, researcher advice to health workers to be more active in providing information and counseling about anemia and how to prevent and handle it.

Keywords: $S G D$, Knowledge, Anemia

\section{PENDAHULUAN}

Anemia sebagai salah satu masalah gizi di Indonesia yang harus di tangani secara serius, terutama pada anemia gizi. Departemen Kesehatan Republik Indonesia dalam rencana pembangunan kesehatan menuju Indonesia 2015 telah menyusun rencana program aksi dan anemia gizi merupakan masalah kesehatan yang berperan dalam penyebab tingginya angka kematian ibu. Penanggulangan anemia gizi menjadi salah satu program potensial untuk meningkatkan kualitas sumber daya manusia yang telah dilaksanakan sejak pembangunan jangka panjang. Prevalensi anemia besi ibu hamil yang tinggi dapat disebabkan oleh tingkat kepatuhan minum tablet besi yang rendah (20-30\%). Anemia defisiensi besi dalam kehamilan adalah kondisi ibu dengan kadar hemoglobin di bawah 11 gr\% pada trimester I dan III atau kadar hemoglobin $<10,5$ gr\% pada trimester II dan merupakan salah satu penyebab kematian pada ibu hamil Anemia merupakan masalah yang dialami oleh 38,2\% ibu hamil di dunia pada tahun 2011. Sekitar setengah dari kejadian anemia tersebut disebabkan karena defisiensi besi (WHO 2015).

Anemia defisiensi besi menjadi penyebab 115.000 kematian ibu per tahun, sehingga program penanggulangan anemia defisiensi besi merupakan langkah yang tepat dalam membantu menurunkan angka kematian ibu. Anemia pada ibu hamil berhubungan dengan meningkatnya risiko kelahiran prematur, kematian ibu dan bayi, serta penyakit infeksi (WHO 2010). Di Indonesia, hasil Riset Kesehatan Dasar (Riskesdas) tahun 2013 menunjukkan angka anemia pada ibu hamil sebesar $37,1 \% \quad$ (Kemenkes 2013), yang menunjukkan bahwa anemia masih merupakan masalah kesehatan masyarakat (WHO 2010).

Angka Kematian Ibu di Indonesia pada tahun 2012 sebesar 359 per $100.000 \mathrm{KH}$ dengan kategori masih tinggi. Berdasarkan kesepakatan SDGs, AKI diharapkan turun menjadi 70 per $100.000 \mathrm{KH}$ pada tahun 2030 mendatang (Kemenkes RI, 2015).

Provinsi Banten merupakan salah satu Provinsi dengan angka kematian ibu (AKI) tinggi di Indonesia (Kemenkes RI 2012). Kota Tangerang adalah wilayah di Provinsi Banten yang memiliki cakupan suplemen besi 90 tablet pada ibu hamil di atas target yang ditetapkan (90\%), namun tingginya angka cakupan di Kota Tangerang tidak sejalan dengan angka anemia ibu hamil yang masih tinggi seperti di Puskesmas Batuceper sebesar 47,9\% (Dinkes Kota Tangerang 2014).

Ibu hamil yang menderita anemia dapat berdampak terhadap janin, seperti bayi lahir prematur, risiko bayi berat lahir rendah (BBLR), kelainan janin, serta meningkatnya risiko gawat janin. Kegiatan suplementasi besi merupakan penanggulangan anemia yang paling banyak dilakukan, di samping upaya lain 
seperti fortifikasi bahan makanan dengan zat besi dan pendidikan gizi lewat strategi komunikasi, informasi, dan edukasi.

Tablet besi selama kehamilan sangat penting karena dapat membantu proses pembentukan sel darah merah sehingga dapat mencegah terjadi nya anemia / penyakit kekurangan darah. Kekurangan zat besi (anemia defisiensi zat besi) selama hamil dapat berdampak tidak baik bagi ibu maupun janin. Perdarahan yang banyak sewaktu melahirkan berefek lebih buruk pada ibu hamil yang anemia. Kekurangan zat besi juga mempengaruhi pertumbuhan janin saat lahir, sehingga berat badannya dibawah normal (BBLR). Akibat lain dari anemia defisiensi besi selama hamil adalah bayi lahir prematur.

Anemia dapat dicegah dengan mengkonsumsi makanan bergizi seimbang dengan asupan zat besi yang cukup untuk memenuhi kebutuhan tubuh. Zat besi dapat diperoleh dengan cara mengkonsumsi daging (terutama daging merah) seperti daging sapi. Zat besi juga dapat ditemukan pada sayuran berwarna hijau gelap seperti bayam dan kangkung, buncis, kacang polong, serta kacang-kacangan.

Perlu diperhatikan bahwa zat besi yang terdapat pada daging lebih mudah diserap tubuh dari pada zat besi pada sayuran atau pada makanan olahan seperti sereal yang diperkuat dengan zat besi.Anemia juga bisa dicegah dengan mengatur jarak kehamilan atau kelahiran bayi. Makin sering seorang wanita mengalami kehamilan dan melahirkan, akan makin banyak kehilangan zat besi dan menjadi makin anemis.

Dalam promosi kesehatan, tidak ada satupun tujuan dan pendekatan atauserangkaian kegiatan yang benar.Hal terpenting adalah bahwa harus mempertimbangkan tujuan dan kegiatan yang dimiliki, sesuai dengan nilai-nilai dan penilaian terhadap kebutuhan klien (Heri D.J M, 2009).

Beberapa model promosi kesehatan dan pendidikan kesehatan dapat membantu pencapaian tujuan yang diharapkan diantaranya adalah dengan diskusi kelompok kecil sebagai salah satu pendekatan pendidikan. Pendekatan ini mempunyai beberapa keuntungan diantaranya lebih memberikan kesempatan untuk bertanya, dapat mengevaluasi pengetahuan siswa secara langsung secara lisan perorang dan pengajar atau penyuluh dapat menguasai audien dengan baik.

Small Group Discussion (SGD) atau diskusi kelompok kecil merupakan elemen belajar secara aktif. Dengan aktivitas kelompok kecil, siswa akan belajar : menjadi pendengar yang baik, memberikan dan menerima umpan balik yang konstruktif, menghormati pendapat orang lain, mendukung pendapat dengan bukti dan lain-lain. Aktivitas diskusi kelompok dapat berupa membangkitkan ide, menyimpulkan poin penting, mengakses tingkat skill dan pengetahuan, memungkinkan memproses outcome pembelajaran pada akhir kelas, dan dapat menyelesaikan masalah.

Berdasarkan hasil survei yang dilakukan di Rumah Bersalin Gebang Medika Kota Tangerang terdapat ibu hamil yang melakukan pemeriksaan kehamilan secara rutin sebanyak 45 orang ibu hamil.

Dari latar belakang tersebut diatas maka peneliti ingin mengetahui "Hubungan Metode Penyuluhan Small Group Discussion dengan Tingkat Pengetahuan Anemia Pada Ibu Hamil di Rumah Bersalin Gebang Medika Kota Tangerang Tahun 2017”.

\section{TUJUAN PENELITIAN}

Untuk mengetahui hubungan Metode penyuluhan Small Group Discussion (SGD) Dengan Tingkat Pengetahuan Anemia Pada Ibu Hamil di Rumah Bersalin Gebang Medika Kota Tangerang.

\section{TINJAUAN TEORITIS}

Small Group discussion (diskusi kelompok kecil) merupakan pembicaraan yang direncanakan dan telah dipersiapkan tentang suatu topik pembicaraan diantara 39 orang peserta (sasaran) dengan seorang 
pemimpin diskusi yang telah ditunjuk. Dalam metode ini semua anggota kelompok bebas berpartisipasi dalam diskusi dan terbuka mengeluarkan pendapat.

Anemia dalam kehamilan ialah kondisi ibu dengan kadar hemoglobin di bawah 11 gr \% pada trimester 1 dan 3 atau kadar < 10,5 gr $\%$ pada trimester 2 . Nilai batas tersebut dan perbedaannya dengan kondisi wanita tidak hamil terjadi karena hemodilusi, terutama pada trimester 2 (Prawirohardjo, 2009). Derajat anemia berdasarkan kadar hemoglobin menurut Manuaba, 2010 :

a. Tidak Anemia: Hemoglobin 11 gr \%

b. Anemia Ringan: Hemoglobin 9 gr\%10 gr\%

c. Anemia Sedang: Hemoglobin 7 gr\%$8 \mathrm{gr} \%$

d. Anemia Berat : Hemoglobin $<7$ gr\%

\section{METODE PENELITIAN}

Rancangan penelitian

ini menggunakan metode survey analitik. Penelitian ini menggunakan data primer yaitu dengan menggunakan teknik kuesioner untuk mengetahui anemia pada ibu hamil di Rumah Bersalin Gebang Medika Kota Tangerang.

\section{POPULASI DAN SAMPEL}

Populasi pada penelitian ini adalah seluruh ibu hamil di Rumah Bersalin Gebang Medika Kota Tangerang adalah sebanyak 45 orang. Jumlah sampel dalam penelitian ini sebanyak 45 orang ibu hamil dengan teknik pengambilan sampel menggunakan total sampling.

\section{TEMPAT DAN WAKTU PENELITIAN}

Penelitian ini dilaksanakan di Jl. Prabu Kian Santang No.30, Kecamatan Periuk, Kelurahan Gebang Raya Kota Tangerang.

Penelitian ini dilakukan pada bulan Juni 2017.

\section{HASIL DAN PEMBAHASAN}

\section{Hasil}

\section{A. Analisis Univariat}

Tabel 1

Distribusi Frekuensi Metode Penyuluhan Small Group Discussion (SGD)

\begin{tabular}{ccc}
\hline $\begin{array}{c}\text { Metode } \\
\text { SGD }\end{array}$ & Frekuensi & Presentasi \\
\hline Dilakukan & 23 & $51,1 \%$ \\
\hline $\begin{array}{c}\text { Tidak } \\
\text { Dilakukan }\end{array}$ & 22 & $48,9 \%$ \\
\hline Total & 45 & $100 \%$ \\
\hline
\end{tabular}

Tabel 1 diatas menunjukan dari total 45 responden, ibu hamil yang dilakukan metode penyuluhan Small Group Discussion ( $S G D$ ) berjumlah 23 responden $(51,1 \%)$, dan yang tidak dilakukan metode penyuluhan Small Group Discussion (SGD) berjumlah 22 responden $(48,9 \%)$.

Table 2

Distribusi Frekuensi

Pengetahuan Anemia Pada Ibu Hamil

\begin{tabular}{ccc}
\hline $\begin{array}{c}\text { Pengetahuan } \\
\text { Anemia }\end{array}$ & Frekuensi & Presentasi \\
\hline Baik & 23 & $55,6 \%$ \\
\hline Tidak Baik & 22 & $44,4 \%$ \\
\hline Total & 45 & $100 \%$ \\
\hline
\end{tabular}

Tabel 2 diatas menunjukan dari total 45 responden, ibu hamil yang menjawab pertanyaan dengan hasil yang baik tentang pengetahuan anemia pada ibu hamil berjumlah 23 responden $(55,6 \%)$, dan ibu hamil yang menjawab pertanyaan dengan hasil yang tidak baik tentang pengetahuan anemia pada ibu hamil berjumlah 22 responden $(44,4 \%)$. 


\section{Tabel 3}

\section{Distribusi Frekuensi Berdasarkan Usia}

\begin{tabular}{ccc}
\hline Variabel & Frekuensi & Presentasi \\
\hline $\begin{array}{c}\text { Tidak } \\
\text { beresiko }\end{array}$ & 26 & $57,8 \%$ \\
\hline Beresiko & 19 & $42,2 \%$ \\
\hline Total & 45 & $100 \%$ \\
\hline
\end{tabular}

Tabel 3 diatas menunjukkan distribusi frekuensi usia responden yang mendapatkan intervensi keseluruhan yaitu tidak beresiko dengan usia 20-35 tahun yaitu sebanyak 26 (57.8\%).

Tabel 4

Distribusi Frekuensi Berdasarkan Pendidikan

\begin{tabular}{ccc}
\hline Variabel & Frekuensi & Presentasi \\
\hline $\begin{array}{c}\text { Pendidikan } \\
\text { tinggi }\end{array}$ & 27 & $60 \%$ \\
\hline $\begin{array}{c}\text { Pendidikan } \\
\text { rendah }\end{array}$ & 18 & $40 \%$ \\
\hline Total & 45 & $100 \%$ \\
\hline
\end{tabular}

Tabel 4 diatas menunjukan distribusi frekuensi berdasarkan pendidikan dengan total 2 responden, pendidikan tinggi berjumlah 27 responden $(60 \%)$ dan pendidikan rendah berjumlah 18 responden $(40 \%)$.

\section{Tabel 5}

Distribusi Frekuensi

Berdasarkan Pekerjaan

\begin{tabular}{ccc}
\hline Variabel & Frekuensi & Presentasi \\
\hline Bekerja & 22 & $48.9 \%$ \\
\hline $\begin{array}{c}\text { Tidak } \\
\text { Bekerja }\end{array}$ & 23 & $51,1 \%$ \\
\hline Total & 45 & $100 \%$
\end{tabular}

Tabel 5 diatas menunjukan distribusi frekuensi berdasarkan pekerjaan dengan total 45 responden, yang bekerja berjumlah 22 responden $(48,9 \%)$ dan yang tidak bekerja berjumlah 23 responden $(51,1 \%)$.

\section{Tabel 6}

Distribusi Frekuensi Berdasarkan Paritas

\begin{tabular}{ccc} 
Variabel & Frekuensi & Presentasi \\
\hline Primipara & 26 & $57,8 \%$ \\
\hline Multipara & 19 & $42,2 \%$ \\
\hline Total & 45 & $100 \%$ \\
\hline
\end{tabular}

Tabel 6 diatas menunjukan distribusi frekuensi berdasarkan paritas dengan total 45 responden, ibu hamil pada primipara berjumlah 26 responden $(57,8 \%)$ dan ibu hamil pada multipara berjumlah 19 responden $(42,2 \%)$.

\section{B. Analisis Data Bivariat}

\section{Tabel 7}

Hubungan Karakteristik Ibu dengan Tingkat Pengetahuan Anemia Pada Ibu Hamil di Rumah Bersalin Gebang Medika Kota Tangerang Tahun 2017

\begin{tabular}{|c|c|c|c|c|c|}
\hline \multirow{2}{*}{$\begin{array}{c}\begin{array}{c}\text { Karakteristik } \\
\text { Ibu }\end{array} \\
\text { Usia }\end{array}$} & \multicolumn{2}{|c|}{ Baik } & \multicolumn{2}{|c|}{ Tidak Baik } & \multirow{2}{*}{$\begin{array}{c}\mathbf{P} \\
\text { Value* }\end{array}$} \\
\hline & $\mathrm{N}$ & $\%$ & $\mathrm{~N}$ & $\%$ & \\
\hline Beresiko & 11 & 24,4 & 8 & 17,8 & \multirow{2}{*}{0,317} \\
\hline Tidak Beresiko & 12 & 26,7 & 14 & 31,1 & \\
\hline \multicolumn{6}{|l|}{ Pendidikan } \\
\hline $\begin{array}{l}\text { Pendidikan } \\
\text { Tinggi }\end{array}$ & 17 & 37,8 & 10 & 22,2 & \multirow[t]{2}{*}{0,050} \\
\hline $\begin{array}{l}\text { Pendidikan } \\
\text { Rendah }\end{array}$ & 6 & 13,4 & 12 & 26,7 & \\
\hline \multicolumn{6}{|l|}{ Pekerjaan } \\
\hline Bekerja & 13 & 28,9 & 9 & 20 & \multirow[t]{2}{*}{0,227} \\
\hline Tidak Bekerja & 10 & 22,2 & 13 & 28,9 & \\
\hline \multicolumn{6}{|l|}{ Paritas } \\
\hline Primipara & 15 & 3,3 & 11 & 24,4 & \multirow[t]{2}{*}{0,223} \\
\hline Multipara & 8 & 17,8 & 11 & 24,4 & \\
\hline
\end{tabular}


Berdasarkan tabel 7 diatas diketahui bahwa dari 45 responden berdasarkan karakteristik ibu hamil yang baik sebanyak 23 (51\%), sedangkan ibu hamil yang tidak baik berdasarkan karakteristik ibu sebanyak $22(48 \%)$. Hasil uji statistik didapatkan P value adalah lebih besar dari $\alpha(0,05)$ sehingga $\mathrm{Ha}$ gagal diterima maka kesimpulannya tidak ada hubungan antara karakteristik ibu dengan tingkat pengetahuan anemia pada ibu hamil.

\section{Tabel 8}

Hubungan Metode penyuluhan Small Group Discussion (SGD) Dengan Tingkat Pengetahuan Anemia Pada Ibu Hamil

\begin{tabular}{|c|c|c|c|c|c|c|c|}
\hline \multirow{3}{*}{$\begin{array}{l}\text { Pengeta } \\
\text { huan }\end{array}$} & \multicolumn{4}{|c|}{ Metode SGD } & \multirow{2}{*}{\multicolumn{2}{|c|}{ Total }} & \multirow{3}{*}{$\begin{array}{c}\mathbf{P} \\
\text { value }\end{array}$} \\
\hline & \multicolumn{2}{|c|}{ Dilakukan } & \multicolumn{2}{|c|}{ Tdk dilakukan } & & & \\
\hline & $\mathbf{F}$ & $\%$ & $\mathbf{F}$ & $\%$ & $\mathbf{F}$ & $\%$ & \\
\hline Baik & 16 & 69.6 & 7 & 30.4 & 23 & 100 & \\
\hline Tidak Ba & 7 & 31.8 & 15 & 68.2 & 22 & 100 & 0.012 \\
\hline Total & 23 & 51.1 & 22 & 48.9 & 45 & 100 & \\
\hline
\end{tabular}

\section{Keterangan : *) Uji Chi Square}

Berdasarkan tabel 8 hasil Analisis Bivariat yang telah dilakukan menggunakan uji chi square, diperoleh nilai $\mathrm{p}$ value 0,012 dan batas kebermaknaannya $\alpha=0,05$, maka dapat disimpulkan $\boldsymbol{\rho}$ pvalue $<\alpha$ maka keputusannya Ha diterima yang berarti terdapat Hubungan Metode penyuluhan Small Group Discussion (SGD) Dengan Tingkat Pengetahuan Anemia Pada Ibu Hamil.

\section{Pembahasan}

Sesuai dengan tujuan penelitian yaitu untuk mengetahui hubungan metode penyuluhan Small Group Discussion (SGD) dengan tingkat pengetahuan anemia pada ibu hamil di Rumah Bersain Gebang Medika Kota Tangerang.

Berdasarkan tabel 8 hasil Analisis Bivariat yang telah dilakukan menggunakan uji chi square, diperoleh nilai pvalue 0,012 dan batas kebermaknaannya $\alpha=0,05$, maka dapat disimpulkan $\rho$ pvalue $<\alpha$ maka keputusannya Ha diterima yang berarti terdapat Hubungan Metode penyuluhan Small Group Discussion (SGD) Dengan Tingkat Pengetahuan Anemia Pada Ibu Hamil.

Penggunaan Metode penyuluhan Small Group Discussion (SGD) terbukti dapat meningkatkan pengetahuan seseorang. Penelitian Purbadewi (2013) menunjukkan adanya peningkatan pengetahuan tentang anemia pada ibu hamil. Hasil penelitian didapatkan ada hubungan metode Small Group Discussion dengan tingkat pengetahuan anemia pada ibu hamil di Puskesmas Moyudan Sleman Yogyakarta. Nilai $P$ value menunjukkan 0,002 .

Peningkatan pengetahuan terjadi karena pada saat dilakukan Small Group Discussion semua anggota kelompok berpartisipasi dalam melakukan diskusi, semua siswi aktif berbicara seperti menggungkapkan pendapatnya, bertanya, menjawab pertanyaan dari fasilitator sampai memecahkan masalah bersama. Faktor lain yang mempengaruhi pengetahuan tentang anemia adalah pendidikan ibu (Wawan \& Dewi, 2011).

Salah satu faktor eksternal yang mempengaruhi pengetahuan adalah adanya informasi. Informasi merupakan fungsi yang penting sebelum di lakukan suatu tindakan bahkan klien dapat mengambil keputusan yang tepat dan memberi kesempatan untuk bertanya lebih lanjut (Wasis, 2013). Dengan adanya informasi maka seseorang akan lebih mengetahui tentang suatu hal.

\section{KESIMPULAN}

Dari analisa hasil penelitian dan pembahasan, maka dapat ditarik kesimpulan dari penelitian ini adalah :

Berdasarkan hasil bivariat dengan menggunakan uji Chi-Square Test diperoleh hasil yang menunjukkan ada hubungan yang signifikan antara metode penyuluhan small group discussion (SGD) dengan tingkat pengetahuan anemia pada ibu hamil di rumah bersalin gebang medika kota tangerang, dengan nilai $\mathrm{p}=0,012(\mathrm{p} \leq$ 
0,05). Sehingga Ha gagal ditolak maka kesimpulannya ada hubungan antara metode penyuluhan small group discussion $(S G D)$ dengan tingkat pengetahuan anemia pada ibu hamil.

\section{SARAN}

\section{Bagi Institusi Pendidikan}

Diharapkan agar dapat menambahkan bahan materi pengetahuan anemia pada mata kuliah kebidanan komunitas di Fikes Universitas Muhammadiyah Tangerang untuk meningkatkan program pendidikan mata kuliah terkait materi penelitian.

\section{Bagi Objek Penelitian}

Diharapkan agar petugas kesehatan menambahkan poster/gambar dan melakukan rutinitas penyuluhan kepada ibu hamil tentang anemia pada kehamilan.

\section{Bagi Peneliti}

Dapat mengambil pengalaman dan menambah wawasan terkait materi tersebut.

\section{Bagi Peneliti Selanjutnya}

Diharapkan agar lebih mencari sumber yang lebih luas lagi agar dapat mengembangkan penelitian dengan menjadikan penelitian ini sebagai bahan rujukan/acuan bagi peneliti selanjutnya.

\section{REFERENSI}

Afifah Mamluatun, Ekawati Heny, $\mathrm{Hj}$. Tarmi. WS. 2016. Pengaruh Small Group Discussion Terhadap Pengetahuan Dismenore Pada Siswi Di SMPN 2 Kepohbaru Kabupaten Bojonegoro : program study s1 keperawatan STIKES Muhammadiyah Lamongan.

Astuti, Maya. 2011. Asuhan Kebidanan Ibu Hamil. Yogyakarta: Fitramaya.

Elsy Noverstiti 2012.Faktor-Faktor Yang Berhubungan Denggan Kejadian Anemia Pada Ibu Hamil Trimester III
Di Wilayah Kerja Puskesmas Air Dingin Kota Padang Tahun 2012.

Hidayat Aziz A. 2007. Metode Penelitian Kebidanan dan Teknik Analisis Data.Jakarta : Salemba Medika.

Https://www.scribd.com/document/27079 0684/Small-Group-Discussion.

Manuaba, Ida, Bagus. 2010. Ilmu Kebidanan, Penyakit Kandungan \& Keluarga Berencana untuk Pendidikan Bidan. Jakarta: EGC.

Moleong, M.A., Prof. DR. Lexy J. 2012. Metodologi Penelitian Kualitatif. Jakarta: PT Remaja Rosda karya.

Notoatmodjo, Soekidjo. 2012. Metodologi Penelitian Kesehatan. Jakarta :Rineka Cipta.

Prawirohardjo, Sarwono. 2006. Ilmu Kebidanan. Jakarta: PT Bina Pustaka Sarwono Prawirohadjo

Prawirohardjo, Sarwono. 2009. Ilmu Kebidanan. Jakarta: PT Bina Pustaka Sarwono Prawirohadjo.

Prawirohardjo, Sarwono. 2010. Ilmu Kebidanan. Jakarta: PT Bina Pustaka Sarwono Prawirohadjo.

Syafrudin,Fratidhina Y. 2009. Promosi Kesehatan Untuk Mahasiswa Kebidanan. Jakarta : Trans Info Media.

Saifuddin, Bari. 2009. Buku Acuan Pelayanan Kesehatan Maternal dan Neonatal.Jakarta: PT Bina Pustaka Sarwono Prawirohadjo.

Qudsiah Chadlirotul, Siti. Djarot Suswanti, Herry. Nurjanah, siti.Hubungan Antara Paritas Dan Umur Dengan Anemia Pada Ibu Hamil Trimester III Tahun 2012 (Skripsi).Semarang :Puskesmas Bangetayu Kecamatan Genuk. 